\title{
The illness experience
}

\section{6 \\ $\mathrm{S}$} ir, I think your son has viral bronchitis. Give him lots of rest and fluids and he should be fine." He looked at me, incredulous.

"Could I be wrong?" I asked him.

"N-No doctor," he stammered.

"Of course I could be," I told him. "If he's not getting better or gets worse, bring him back in."

In my third year of medical school, I went to an emergency department with severe headaches and impaired balance. The neurology resident told me that it was probably migraines and suggested an MRI (in 12-14 weeks). I bugged an attending neurologist on his lunch break and he agreed, "but we'll do a CT just in case." The result? Massive hydrocephalus and an egg-sized lesion in my fourth ventricle. I recovered and finished training, completed residency and started practice as a rural family doctor. Alas, the tumour grew back and I needed further surgery. The lesion was benign and is gone, but I have facial paralysis, uncorrectable diplopia and ongoing disabling ataxia. Luckily, I bought a ton of disability insurance, so my children weren't destroyed by my misfortune.

We deal with uncertainty every day. I think the care I've received has been

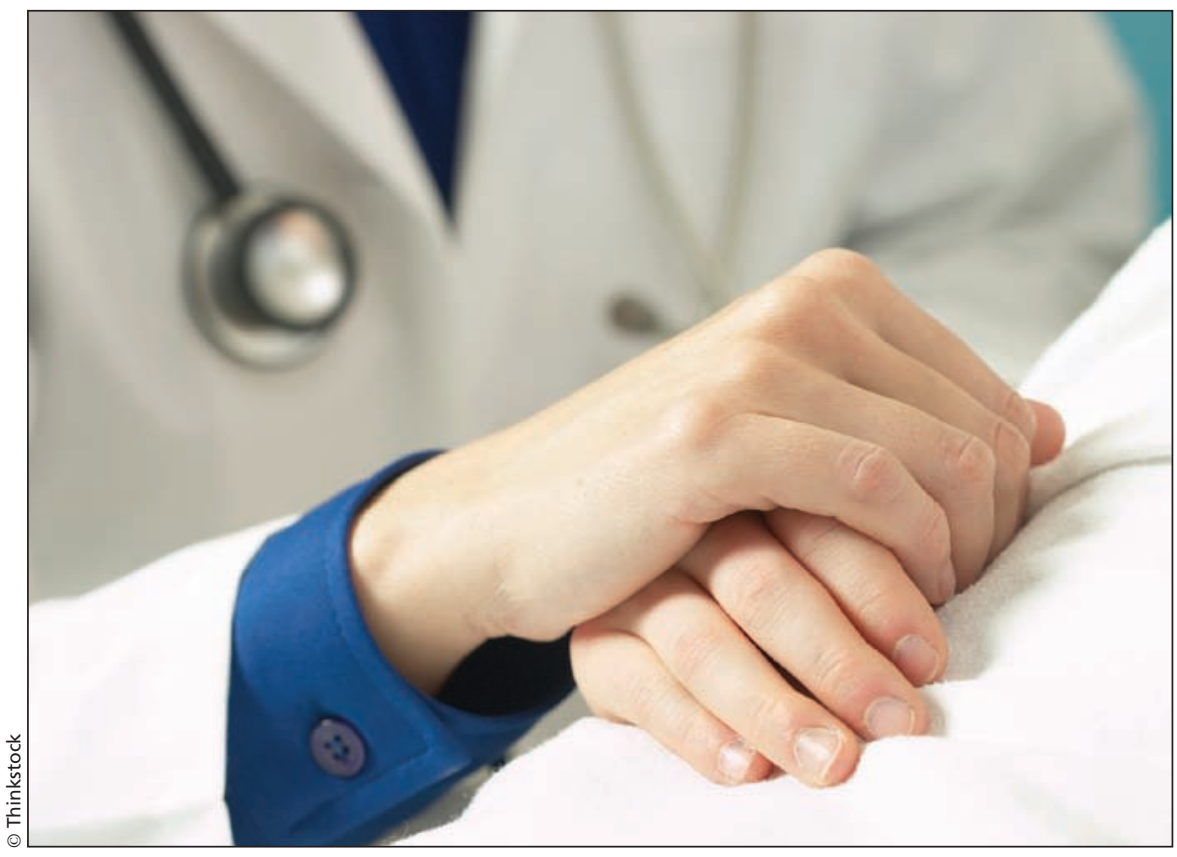

cians constantly deal with uncertainties.

I really wish that my experience was unique, but doctors get sick, deal with ill loved ones, and become disabled all the time. In my case, that gets me thinking philosophically, which brings me to the idea of uncertainty.

I have experienced some amazing things. I have delivered babies, performed minor surgeries, worked on-call

\section{As a physician, am I better prepared to deal with things when they go poorly?}

fantastic, and the support from my friends, family and colleagues amazing, but friends and family are bothered by "missed diagnoses" and poor outcomes. I wonder if maybe, as a physician myself, I am better prepared to deal with things when they go poorly. Every person knows intuitively that getting up in the morning and driving to work, by itself, has risks, but physi- in the emergency department, made house calls and provided palliative care. I taught physicians-in-training, served on the regional health board in my province, and did my best to be a good citizen in my community. I'm very fortunate in that, cognitively, I'm still very sharp and could still contribute someday. Day-to-day life is ridiculously difficult, but I realize that it could be a whole lot harder. I miss being able to help people struggling with illnesses worse than mine. It probably wasn't until I became ill that I realized just how much of a difference physicians can make, including helping their patients to manage the uncertainty of illness.

There is uncertainty in everything we do. People who are ill realize that each day holds the potential for something fantastic $\ldots$ or disaster. Doctors are uniquely positioned to think in terms of risks and benefits. An ill doctor gets to see both. There is risk involved, but it's not theoretical - the ill doctor lives it. Physicians should do their best to guide their patients through the uncertainties of illness. As a patient battling an illness, I can certainly explain how frightening it is. Doctors should be able to step back a little, honestly discuss possibilities and advise. Patients need that.

\section{Mark Langer MD}

Edmonton, Alta.

CMAJ 2014. DOI:10.1503/cmaj.131304 